\title{
Metabolic recovery of adipose tissue is associated with improvement in insulin resistance in a model of experimental diabetes
}

\author{
Julie Takada, Miriam Helena Fonseca-Alaniz, Tarcila Beatriz Ferraz de Campos, Sandra Andreotti, \\ Amanda Baron Campana, Maristela Okamoto, Cristina das Neves Borges-Silva, \\ Ubiratan Fabres Machado and Fabio Bessa Lima \\ Department of Physiology and Biophysics, Institute of Biomedical Sciences, University of Sao Paulo, 1524 Prof Lineu Prestes Avenue, 05508-900, \\ Sao Paulo, Brazil \\ (Correspondence should be addressed to F B Lima; Email: fabio@icb.usp.br)
}

\begin{abstract}
Obesity and insulin resistance are highly correlated with metabolic disturbances. Both the excess and lack of adipose tissue can lead to severe insulin resistance and diabetes. Adipose tissue plays an active role in energy homeostasis, hormone secretion, and other proteins that affect insulin sensitivity, appetite, energy balance, and lipid metabolism. Rats with streptozotocin-induced diabetes during the neonatal period develop the classic diabetic picture of hyperglycemia, hypoinsulinemia, and insulin resistance in adulthood. Low body weight and reduced epididymal (EP) fat mass were also seen in this model. The aim of this study was to investigate the glucose homeostasis and metabolic repercussions on the adipose tissue following chronic treatment with antidiabetic drugs in these animals. In the 4th week post birth, diabetic animals started an 8 -week treatment with pioglitazone, metformin, or insulin.
\end{abstract}

Animals were then killed, EP fat pads were excised, and blood samples were collected for biological and biochemical assays. Pioglitazone and insulin treatments, but not metformin, reduced hyperglycemia, polydipsia, and polyphagia. Although all antidiabetic therapies improved insulin sensitivity, this was particularly noteworthy in the pioglitazone-treated rats. Furthermore, a recovery of adipose mass and insulin levels were observed in pioglitazone- and insulin-, but not metformin-treated animals. Treatments with insulin or pioglitazone were able to correct significantly, but not completely, the metabolic abnormalities, parallel to full recovery of adipose mass, indicating that not only the low insulin levels but also the lack of adipose tissue might play a significant role on the pathophysiology of this particular diabetes model.

Journal of Endocrinology (2008) 198, 51-60

\section{Introduction}

Hyperglycemia in diabetes mellitus (DM) is a result of inadequate insulin secretion and reduced systemic responsiveness to insulin (DeFronzo et al. 1992). Obesity, most notably central adiposity, is one of the main features of the metabolic syndrome, leading to a greater free fatty acid (FFA) flux, which inhibits insulin action in insulin-sensitive tissues (Randle et al. 1963). Insulin resistance coupled with obesity triggers many metabolic abnormalities that increase cardiovascular risk (Lebovitz et al. 1995). To reinforce this idea, the surgical removal of visceral adipose mass from obese animals not only improved insulin resistance but also reduced cardiovascular risk (Barzilai et al. 1999).

White adipose tissue (WAT) plays a crucial role in energy homeostasis to include insulin sensitivity, appetite control, energy balance, immunity, angiogenesis, blood pressure, and lipid metabolism, by secreting a wide range of bioactive proteins termed 'adipokines' (Fischer-Posovszky et al. 2007). Interestingly, both the excess (obesity) and lack (lipoatrophy) of WAT bring severe metabolic consequences such as insulin resistance, hypertriacylglycerolemia, diabetes, and fatty liver (Gavrilova et al. 2000). These derangements are correctable by interventions on adipose tissue. Transplantation of WAT to a lipodystrophic animal results in impressive improvement in insulin sensitivity and glycemia (Gavrilova et al. 2000). Hence, a critical amount of fat mass seems necessary to allow the adequate lipid storage avoiding other tissues or organs skeletal muscle or liver - from the occurrence of abnormal intracellular lipid infiltration that aggravates insulin resistance (Kelley et al. 2002, Song 2002).

Thiazolidinediones (TZDs) are potent agonists of the peroxisome proliferator-activated receptor $\gamma(\operatorname{PPAR} \gamma)$, a nuclear receptor expressed in insulin target tissues, such as WAT, skeletal muscle, and liver (Tontonoz et al. 1994, Parulkar et al. 2001). TZDs improve insulin sensitivity by increasing glucose utilization and inhibiting endogenous glucose production (Miyazaki et al. 2002, Boden et al. 2003). As WAT expresses the highest levels of PPAR $\gamma$, it is a preferable target for TZD (Sharma \& Staels 2007). Its insulin-sensitizing effect also includes stimulation of adipogenesis, increasing the number of small adipocytes, which are more insulin sensitive 
than the large and lipid-laden adipose cells (Tontonoz et al. 1994, Okuno et al. 1998). A known side effect of TZD use is weight gain (Fonseca 2003, Wilding 2006). In addition, TZDs improve lipid profile, lowering FFAs and increasing high density lipoprotein (HDL)-cholesterol levels in diabetic patients (Maggs et al. 1998).

Metformin, a biguanide widely used for DM therapy, has antidiabetic effects relying on the improvement in peripheral insulin sensitivity without stimulating insulin secretion and weight gain (Natali \& Ferrannini 2006). Additionally, metformin has beneficial effects on circulating lipid levels (Wu et al. 1990).

In our previous study, experimental diabetes was induced by streptozotocin (STZ) in rats during the neonatal period (5th day of life). As a result of $\beta$-cell cytotoxicity, these animals developed clinical features similar to the ones presented by diabetic patients, such as hyperglycemia, hypoinsulinemia, polyphagia, polydipsia, polyuria, and glycosuria. Such features persisted and were aggravated throughout adulthood (Takada et al. 2007). Interestingly, the rats also presented a lower body weight gain and a marked reduction in epididymal (EP) fat mass along with impaired glucose metabolism in isolated adipocytes. Therefore, considering the importance of WAT and its adipokines for the regulation of energy metabolism, the aim of this study was to evaluate the repercussions oflong-term treatment from weaning to adulthood with antidiabetic drugs on the adipose tissue metabolism in this diabetes model.

\section{Materials and Methods}

\section{Materials}

All chemicals and drugs: sodium citrate, STZ, collagenase, Earle's salts, HEPES, BSA (EHB), sodium pyruvate, $\mathrm{NaHCO}_{3}$, sulfuric acid, isopropanol, and $n$-heptane were from Labsynth (Diadema, SP, Brazil), AMRESCO (Solon, OH, USA), or Sigma-Aldrich Chemical. Pioglitazone chloridrate, neutral protamine hagedorn $(\mathrm{NPH})$ insulin, and metformin chloridrate were from Takeda Chemical Industries Ltd (Osaka, Japan), Novo Nordisk (Montes Claros, MG, Brazil) and Merck Santé respectively. Sodium thiopental was from Cristalia (Sao Paulo, SP, Brazil) and 2-deoxy-D- $\left[{ }^{3} \mathrm{H}\right]$-glucose and D- $\left[\mathrm{U}_{-}{ }^{14} \mathrm{C}\right]$-glucose were from Amersham Life Sciences. Primers, DNase 1, SuperScript II, Taq DNA polymerase, and dNTPs were from Invitrogen Life Technologies. All procedures were carried out according to the manufacturer's instructions.

\section{Animals}

Five-day-old male Wistar rats were fasted (separated from their mothers) for $8 \mathrm{~h}$. The diabetic (STZ) group was injected with STZ (120 mg/kg b.w., intraperitoneally) freshly diluted in citrate buffer $(10 \mathrm{mM}, \mathrm{Na}$ citrate, $\mathrm{pH} 4 \cdot 5)$. The non-diabetic control (C) group received only the vehicle in equivalent volume.

\section{Treatment of animals}

After weaning (21 days), glycemia was determined in STZtreated animals and only those with levels above $150 \mathrm{mg} / \mathrm{dl}$ were selected for this study. The animals were then randomly divided into five groups and the treatment started in the 4th week after their birth. Group D, non-treated STZ-diabetic animals; STZ-diabetic treated groups: group $M$, metformin (diluted in drinking water, $450 \mathrm{mg} / \mathrm{kg} \mathrm{b.w.);} \mathrm{group} \mathrm{P,}$ pioglitazone (orally, $5 \mathrm{mg} / \mathrm{kg} \mathrm{b.w.);} \mathrm{and,} \mathrm{group} \mathrm{I,} \mathrm{insulin}$ (NPH insulin s.c. injected twice daily, $0.5 \mathrm{U} / 100 \mathrm{~g} \mathrm{b.w.} \mathrm{at}$ $0800 \mathrm{~h}$ and $1.0 \mathrm{U} / 100 \mathrm{~g} \mathrm{b.w}$. at $1600 \mathrm{~h}$ ); and, finally group C, a non-diabetic control group.

The animals (three per cage) were kept under a $12 \mathrm{~h}$ light: $12 \mathrm{~h}$ darkness cycle (lights on at $0700 \mathrm{~h}$ ) at $23{ }^{\circ} \mathrm{C}$ and with full access to food (Nuvilab balanced chow pellets, Nuvital SA, Columbo, Brazil) and water for the following 9 weeks. Apart from each experimental group, another group of animals was individually monitored for water and food intake.

Body weight and glycemia were measured weekly from weaning to killing (12-week old). Tail blood was collected for glucose determination using a glucometer (Lifescan, Scotland, UK).

\section{i.v. Glucose and insulin tolerance test (iv GTT and ivITT)}

The tests were performed at $0800 \mathrm{~h}$ after $12 \mathrm{~h}$ of fasting. In 11-week-old animals, under slight anesthesia (Sodium tiopental, $2 \mathrm{mg} / 100 \mathrm{~g}$ b.w.), the glucose load (75 mg glucose $/ 100 \mathrm{~g}$ b.w.) was injected as a 'bolus' via dorsal vein of the penis and tail blood samples were collected at $0,5,20$, and $60 \mathrm{~min}$ after injection for glucose determination.

A similar procedure was performed for ivITT. The insulin load (75 mU/100 g b.w.) was injected as a 'bolus' and the blood glucose levels were determined at $0,3,6,9,12$, and $30 \mathrm{~min}$ after injection.

\section{Killing}

In the 12th week, the animals (12-h fasted) were decapitated under slight anesthesia (Na pentobarbital $4 \mathrm{mg} / 100 \mathrm{~g} \mathrm{b.w.)} \mathrm{at}$ $0800 \mathrm{~h}$ and trunk blood was collected. The serum was used for insulin, leptin, C-peptide, glucose, FFAs, and triacylglycerol (TAG) determinations. After abdominal wall opening, the EP fat pads were excised and processed for adipocyte isolation. The described procedures followed the institutionally approved protocol in accordance with the Ethical Principles in Animal Research adopted by the Institute of Biomedical Sciences Ethical Committee for Animal Research (CEEA) (no. 032/99) and the UFAW Handbook on the Care and Management of Laboratory Animals.

\section{Adipocyte isolation}

Adipocytes were isolated with collagenase as previously described (Rodbell 1964). The cell suspensions were kept in a $20 \%$ final concentration (corresponding to $\sim 10^{6}$ cells $/ \mathrm{ml}$ ) 
and were maintained in water bath for $30 \mathrm{~min}$ before initiating the biological tests described below. Adipocyte viability and number were determined as previously described (Fine \& Digirolamo 1997).

\section{Insulin-stimulated 2-deoxy-D-glucose uptake (2DGU)}

Isolated adipocytes (20\% cell suspension in EHB buffer) were incubated in the presence or absence of a maximally insulinstimulating concentration $(10 \mathrm{nmol} / \mathrm{l})$. After $30 \mathrm{~min}$ of incubation, basal and maximal rates of 2DGU (in triplicates) were evaluated according to protocols described elsewhere (Takada et al. 2007).

Incorporation of $\mathrm{D}_{-}\left[\mathrm{U}_{-}{ }^{14} \mathrm{C}\right]$-glucose into lipids, and its conversion into ${ }^{14} \mathrm{CO}_{2}$

From a 20\% adipocyte suspension in Krebs/Ringer/phosphate buffer ( $\mathrm{pH} 7 \cdot 4)$, with BSA $1 \%$ and glucose $2 \mathrm{mmol} / 1$ (at $37{ }^{\circ} \mathrm{C}$ ) and saturated with a gas mixture of $\mathrm{CO}_{2} 5 \% / \mathrm{O}_{2}$ $95 \%, 450 \mu \mathrm{l}$ aliquots were transferred to polypropylene test tubes $(17 \times 100 \mathrm{~mm})$, containing $\mathrm{D}-\left[\mathrm{U}-{ }^{14} \mathrm{C}\right]$-glucose (1850 Bq per tube), in the presence or absence of insulin $(10 \mathrm{nmol} / \mathrm{l})$. These samples were then incubated $(500 \mu \mathrm{l}-$ final volumes) for $1 \mathrm{~h}$ at $37^{\circ} \mathrm{C}$ in orbital shaker water bath (150 r.p.m.) and the tubes (with a $\mathrm{CO}_{2} \quad 5 \% / \mathrm{O}_{2}$ 0, 5\% atmosphere) were closed with a rubber stopper. At the end of incubation, the stopper was removed and $200 \mu$ of $\mathrm{H}_{2} \mathrm{SO}_{4}$ (4 M) was quickly pipetted and another vial containing a piece of filter paper $(2 \times 4 \mathrm{~cm})$ moistened with $200 \mu \mathrm{l}$ of ethanolamine was placed (mouth to mouth) on top of incubation tubes. The assembled tubes were sealed with a band of parafilm and maintained for additional $30 \mathrm{~min}$ for collecting the ${ }^{14} \mathrm{CO}_{2}$ released from the mixture. The vial on top of the incubation tubes was then disconnected, filled with scintillation cocktail (Universol, ICN Pharmaceuticals, Costa Mesa, CA, USA), and the radioactivity was counted in a $\beta$-counter (Beckman L5-8000, Palo Alto, CA, USA). The remaining reaction mixture was treated with $2.5 \mathrm{ml}$ of Dole's reagent (isopropanol, $n$-heptane, and $\mathrm{H}_{2} \mathrm{SO}_{4}, 4: 1: 0 \cdot 25 \mathrm{vol} / \mathrm{vol}$ per vol) for lipid extraction. The tube was vortexed three times in the next $30 \mathrm{~min}$ and $1.5 \mathrm{ml}$ of $n$-heptane and $1.5 \mathrm{ml}$ of distilled water were added, the tube was vortexed and the mixture decanted for $5 \mathrm{~min}$. Five hundred microliters of the upper phase was collected in duplicates to a scintillation vial for the determination of radioactivity trapped into lipids. The results were expressed as nanomoles of ${ }^{14} \mathrm{CO}_{2}$ released and of glucose incorporated into lipids per $10^{6}$ cells $\times$ h.

\section{Measurement of lipolysis}

Lipolytic activity was performed in isolated adipocytes as described elsewhere (Borges-Silva et al. 2005). The glycerol content of incubated medium was measured using the free glycerol determination kit (Sigma-Aldrich) and was used as an index of lipolysis, expressed as nanomoles of glycerol released by $10^{6}$ cells per hour.

\section{Hormones, fatty acids and glucose measurements}

Serum glucose, TAG, and FFA were determined by enzymatic methods using commercial kits (Glicose SL-e, CELM, Sao Paulo, Brazil; K 055-1, Quibasa, Belo Horizonte, MG, Brazil; HR (2), WAKO, Osaka, Japan respectively). Leptin, insulin, and C-peptide levels were quantified using rat leptin, insulin, and C-peptide RIA kits (Linco Research, St Charles, MO, USA).

\section{Estimated pancreatic insulin content (per 100 islets)}

Rat pancreatic islets were isolated by collagenase digestion as described elsewhere (Lacy \& Kostianovsky 1967). One hundred islets per pancreas were pooled, homogenized, and insulin content was quantified using a rat insulin RIA kit (Linco Research).

\section{Reverse transcriptase-PCR (RT-PCR) assay for glucose} transporter 4 (GLUT4) gene expression

Total RNA was extracted from EP fat using Trizol solution (Invitrogen), according to the manufacturer's specifications (Chomczynski \& Sacchi 1987). After DNase treatment, cDNA was synthesized from $5 \mu \mathrm{g}$ of total RNA using Moloney murine leukemia virus reverse transcriptase (Superscript II kit). We amplified $2 \mu \mathrm{l}$ of the cDNA product on a Gradient Mastercycler (Eppendorf, Hamburg, Germany), using specific sets of primers: rat GLUT4: sense primer, 5'-GCTGTGCCATCTTGATGACGG-3'; antisense primer, 5'-TGAAGAAGCCAAGCAGGAGGA C-3'; rat RPL-37a: sense primer, 5'-CAAGAAGGTCGGGATCGTCG-3'; antisense primer, 5'-ACCAGGCAAGTCTCAGGAGGTG-3'.

After initial denaturation at $95{ }^{\circ} \mathrm{C}$ for $2 \mathrm{~min}$, the temperatures and times used for GLUT4 were: 29 cycles at $95{ }^{\circ} \mathrm{C}(30 \mathrm{~s}), 59 \cdot 5^{\circ} \mathrm{C}(30 \mathrm{~s}), 72{ }^{\circ} \mathrm{C}(45 \mathrm{~s})$; and for RPL-37a (used as an internal constitutive control): 20 cycles at $95^{\circ} \mathrm{C}$ $(30 \mathrm{~s}), 57 \cdot 0^{\circ} \mathrm{C}(30 \mathrm{~s}), 72{ }^{\circ} \mathrm{C}(30 \mathrm{~s})$. The amplified products were resolved in a $2 \%$ agarose gel and analyzed by scanning densitometry (Eagle Eye-Stratagene, model 401304, software Eagle Sight 3.2). Samples were normalized to the quantity of RPL-37a signal produced by RT-PCR and presented as arbitrary units (AU) of GLUT4 mRNA relative to control.

\section{Western blotting for GLUT4 protein}

Three subcellular membrane fractions of adipose tissue were prepared as described elsewhere (Okamoto et al. 2004). Tissue samples were homogenized and processed to obtain the following fractions: fat-free extract, plasma membrane (PM), and microsome. GLUT4 protein was assessed by western blotting method, as previously described (Okamoto et al. 2004). The intensity of the blots was quantified by densitometry using 
Table 1 Body weight, glucose levels, food and water intake, and estimated pancreatic insulin content of 12-week-old animals. Values are mean \pm s.E.M., $n=10$

\begin{tabular}{|c|c|c|c|c|c|}
\hline & Group C & Group I & Group P & Group M & Group D \\
\hline Body weight (g) & $296 \cdot 0 \pm 8 \cdot 6^{\mathrm{a}}$ & $282 \cdot 0 \pm 9 \cdot 1^{\mathrm{a}, \mathrm{c}}$ & $265 \cdot 8 \pm 5 \cdot 6^{a, c}$ & $258 \cdot 0 \pm 8 \cdot 7^{\mathrm{b}, \mathrm{c}}$ & $252 \cdot 0 \pm 6 \cdot 9^{b}$ \\
\hline Lee index $\left(\mathrm{g}^{1 / 3} / \mathrm{cm}\right)$ & $29 \cdot 4 \pm 0 \cdot 1^{a}$ & $29 \cdot 2 \pm 0 \cdot 1^{\mathrm{a}, \mathrm{b}}$ & $29 \cdot 2 \pm 0 \cdot 2^{a, b, c}$ & $28 \cdot 8 \pm 0 \cdot 2^{\mathrm{b}, \mathrm{c}}$ & $28 \cdot 9 \pm 0 \cdot 1^{a, b}$ \\
\hline Blood glucose (mg/dl) & $104 \cdot 2 \pm 3 \cdot 1^{\mathrm{a}}$ & $144 \cdot 2 \pm 14 \cdot 4^{\mathrm{a}, \mathrm{c}}$ & $128 \cdot 2 \pm 9 \cdot 0^{\mathrm{a}, \mathrm{c}}$ & $169 \cdot 0 \pm 23 \cdot 9^{a, b, c}$ & $235 \cdot 9 \pm 25 \cdot 2^{b}$ \\
\hline $\begin{array}{l}\text { Pancreatic insulin } \\
\text { content (nM/islet) }\end{array}$ & $1165 \cdot 2 \pm 83 \cdot 6^{\mathrm{a}}$ & $1464 \cdot 5 \pm 124 \cdot 1^{\mathrm{a}, \mathrm{c}}$ & $1403 \cdot 3 \pm 205 \cdot 6^{a, c}$ & $151 \cdot 8 \pm 69 \cdot 2^{b}$ & $174.9 \pm 88 \cdot 9^{b}$ \\
\hline Food intake (g/24 h) & $24 \cdot 7 \pm 0 \cdot 7^{\mathrm{a}}$ & $26 \cdot 4 \pm 0 \cdot 4^{\mathrm{a}, \mathrm{c}, \mathrm{d}}$ & $22 \cdot 8 \pm 1 \cdot 7^{\mathrm{a}, \mathrm{d}}$ & $30 \cdot 1 \pm 0 \cdot 3^{a, b, c}$ & $33 \cdot 8 \pm 2 \cdot 0^{b}$ \\
\hline Water intake $(\mathrm{ml} / 24 \mathrm{~h})$ & $50 \cdot 0 \pm 1 \cdot 7^{a}$ & $50 \cdot 9 \pm 4 \cdot 5^{a, b}$ & $51 \cdot 0 \pm 1 \cdot 5^{a, b}$ & $83 \cdot 9 \pm 2 \cdot 5^{a}$ & $117 \cdot 5 \pm 4 \cdot 8^{\mathrm{C}}$ \\
\hline
\end{tabular}

Letters after each value that are not shared mean that the results are significantly different $(P<0 \cdot 05)$.

Image Master 1D software (Pharmacia Biotech). Results were expressed as AU per microgram of total protein subjected to electrophoresis (AU/ $\mu \mathrm{g}$ of protein), and GLUT4 content per gram of total EP fat pad (AU/g), normalizing as $100 \%$ the protein expression in control rat tissues.

\section{Statistical analysis}

Results were expressed as mean \pm s.E.M. One-way ANOVA test was adopted to evaluate differences among groups. Bonferroni post hoc test was used to detect difference between groups. The analysis was performed by the statistical software package GraphPad Prism version 4.0 for Windows (GraphPad Software, San Diego, CA, USA). Differences were considered significant when $P<0 \cdot 05$.

\section{Results}

Effect of treatment on body weight, glucose levels, pancreatic insulin content, and other clinical parameters

Reduced body weight, seen in the non-treated diabetic group (D), was only fully recovered with insulin treatment. In groups $\mathrm{P}$ and $\mathrm{M}$, treatment did not significantly affect this parameter (Table 1). The Lee index was determined at killing. $\mathrm{P}$ and I therapies brought these values close to control levels while $\mathrm{M}$ was completely ineffective.

Since the first determinations, blood glucose levels (at $0900 \mathrm{~h}$ ) were significantly higher in group D. Treatments with pioglitazone, insulin, or metformin did lower glycemia, although the values were not completely normalized (Fig. 1).

Group D consistently presented higher food and water intake. This diabetic condition was completely corrected only in groups $\mathrm{I}$ and $\mathrm{P}$ while in M-treated animals, it was partially improved. Table 1 also displays lower pancreatic insulin content in the nontreated diabetic group. A significant and complete recovery was seen in groups I and P. Metformin therapy was ineffective.

\section{Long-term treatment improved insulin sensitivity}

The glycemic curves during the ivGTTwere distinct between groups D and C. The glucose tolerance improved, although not completely in groups I, P, and M. In Fig. 2 (insert), in which the area under the curve is depicted, pioglitazone showed the best result among the treatments.

Figure 3A shows glycemic curves during ivITTobtained by diabetic and non-diabetic groups. The rate constants $\left(K_{\mathrm{ITT}}\right)$ of glucose disappearance, calculated as described elsewhere (Bonora et al. 1989) (see Fig. 3, insert), were higher in groups $\mathrm{P}, \mathrm{I}$, and $\mathrm{M}$ compared with $\mathrm{D}$ and similar to control group.

Effect of treatment on hormones, blood glucose, TAG and FFA

Serum from 12-h fasted rats was used for biochemical analysis (Table 2). There was a reduction in glucose and TAG levels in all treated (I, P, and M) groups. A significant reduction on the elevated FFA levels (seen in group D) was obtained only in group P. Insulin levels improved significantly in groups I and $\mathrm{P}$, but not in $\mathrm{M}$. Pioglitazone, but not insulin or metformin treatments, was able to correct the reduced C-peptide and leptin levels seen in group D.

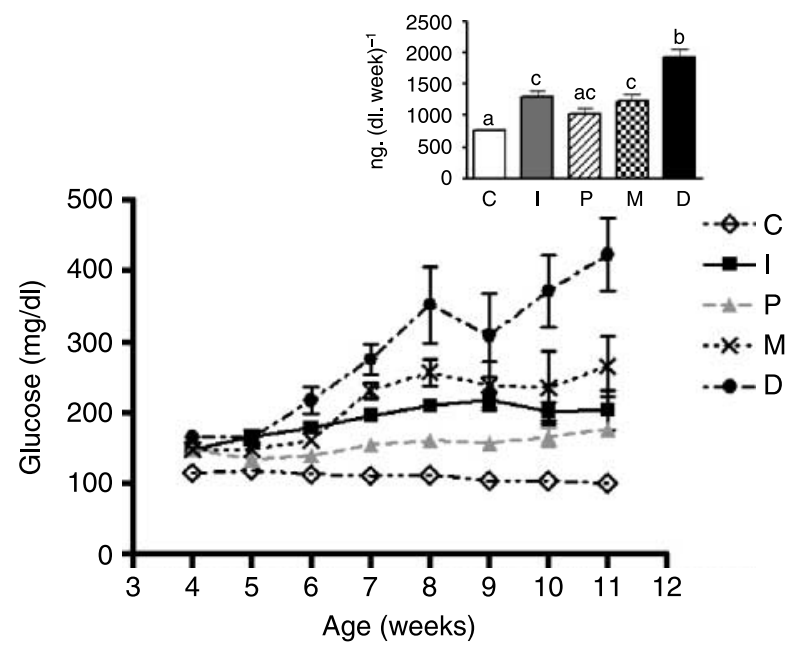

Figure 1 Effect of insulin, pioglitazone, or metformin treatments on blood glucose profile in STZ-induced diabetes. Tail blood samples were weekly collected from awaken rats in fed state at $0800 \mathrm{~h}$. Insert: area under the curve of blood glucose. Values are mean \pm S.E.M., $n=10$. *Note that above each bar, there are letters. Bars sharing the same letters do not differ statistically. Letters not shared indicate statistically significant differences $(P<0 \cdot 05)$. 


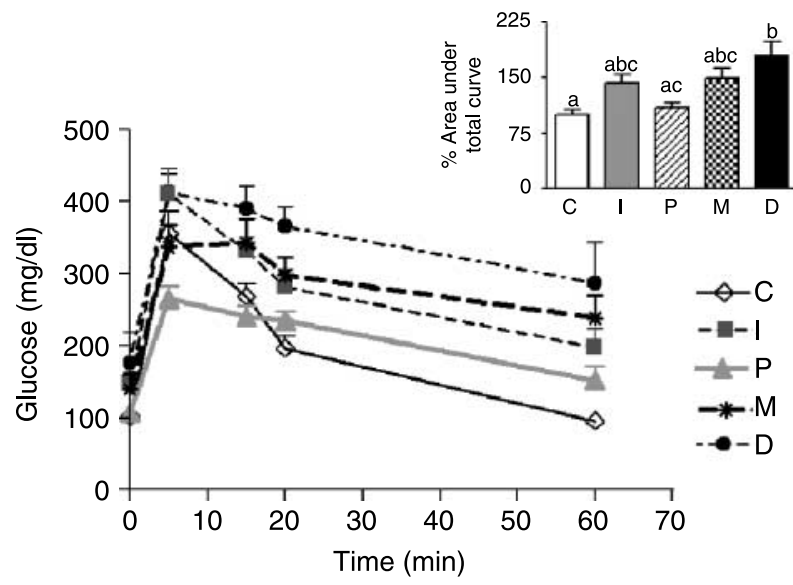

Figure 2 i.v. Glucose tolerance test (ivGTT). A glucose load (75 mg/100 g b.w.) was injected as a 'bolus' through the dorsal vein of the penis. The main graph shows the glycemic curve and the upper insert, the area under the curve. Values are mean \pm s.E.M., $n=10$. Letters above bars: see explanation in Fig. 1 .

\section{Insulin and pioglitazone treatments increased adipose mass}

Untreated diabetes significantly reduced the EP fat mass as well as the adipocyte size, which were corrected after insulin or pioglitazone treatments (Fig. 4A and B). Group M did not reproduce the same results and both the EP fat mass and the cell size did not differ from that of group D.

\section{Effect of treatment on insulin-stimulated $2 D G U$}

Significant reductions were seen in basal and maximally insulin-stimulated $2 \mathrm{DG}$ uptake rates in group D. Both basal

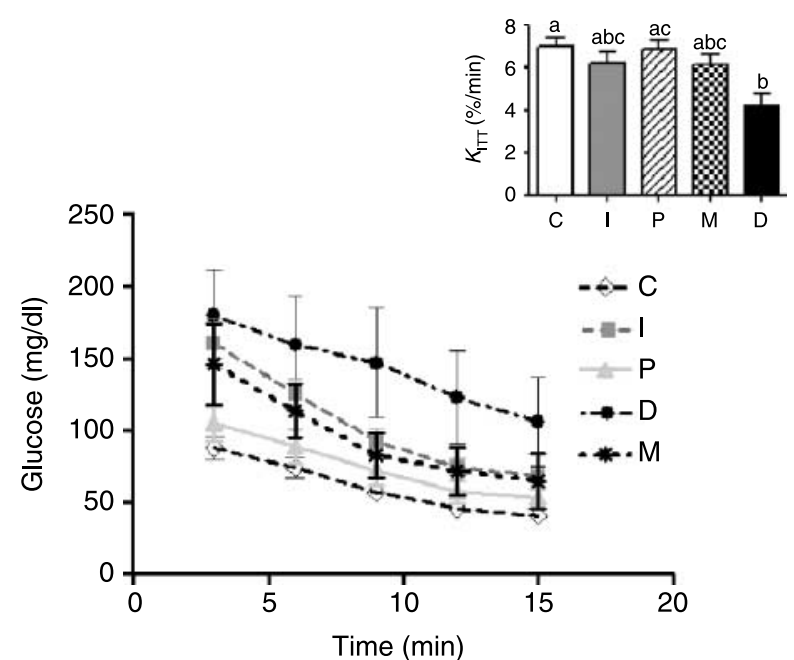

Figure 3 i.v. Insulin tolerance test (ivITT). An insulin load (75 mU/100 g b.w.) was injected as a 'bolus' through the dorsal vein of the penis. The main graph shows the glycemic curve and upper insert, glucose disappearance rate $\left(K_{\mathrm{ITT}}\right)$ during the test. Values are mean \pm s.E.M., $n=10$. Letters above bars: see explanation in Fig. 1. and maximal 2DGU rates were significantly recovered in I- and $\mathrm{P}$-, but not $\mathrm{M}$-treated rats, indicating an important improvement and an almost complete normalization (Fig. 5).

\section{Insulin and pioglitazone increased GLUT4 protein and its $m R N A$ expression}

The GLUT4 protein and its mRNA content were also assessed in EP fat pads to check whether the improved insulin-stimulated 2-DG uptake (in groups I and P) has a molecular support by an up-regulation of this protein expression. Group D showed a significant reduction in GLUT4 levels in PM and microsomal (M) fractions, which apparently was not modified by metformin, but completely recovered by insulin or pioglitazone treatment (Fig. 6). When adjusted by fat pad weight (Table 3), the effects of the treatments became even clearer. Both P and I sustained the GLUT4 content in WAT at normal levels while M showed no effect. The defective expression of GLUT4 mRNA levels was only fully corrected by pioglitazone $(112 \cdot 3 \%)$ and insulin (96.6\%) treatments (Fig. 7).

\section{Effect of treatment on glucose oxidation and its incorporation} into lipids

The glucose oxidation rates, significantly reduced in D group, were corrected by pioglitazone or insulin treatment, reaching values even higher than the ones found in group $\mathrm{C}$ (Fig. 8A). The ability of adipocytes to incorporate glucose into lipids was also improved in groups I and P. Metformin did not work on these aspects.

\section{Insulin or pioglitazone reduced lipolytic activity}

Figure 9 shows an elevated lipolytic activity in group D, which was partially reduced by metformin treatment. Pioglitazone and insulin therapies promoted significant reductions, with values even lower than that in group $\mathrm{C}$ ones.

\section{Discussion}

Early treatment with antidiabetic therapies ameliorated the metabolic condition, by improving fasting glucose levels and insulin sensitivity. However, the degree of improvement varied among the diabetic treated groups.

We detected no effect on body weight gain with metformin treatment, which confirms other studies associating this biguanide with no change or loss of body weight in diabetic patients (Després 2003, Setter et al. 2003). The insulinsensitizing effects of metformin - mainly in liver and muscle were capable of partially restoring the glucose and insulin homeostasis as seen by the reduced area under the glycemic curve (in ivGTT) and the increased glucose utilization by tissues - represented by $K_{\text {ITT }}$ values. On the other hand, the low pancreatic insulin content and reduced insulin and 
Table 2 Effect of treatment on serum insulin, leptin, C-peptide, triacylglycerol (TAG), and free fatty acid (FFA) levels in 12-h fasted animals. Values are mean \pm S.E.M., $n=10$

\begin{tabular}{|c|c|c|c|c|c|}
\hline & Group C & Group I & Group P & Group M & Group D \\
\hline Insulin (ng/ml) & $1 \cdot 62 \pm 0 \cdot 3^{\mathrm{a}}$ & $1 \cdot 29 \pm 0 \cdot 2^{\mathrm{a}, \mathrm{c}}$ & $1 \cdot 29 \pm 0 \cdot 2^{\mathrm{a}, \mathrm{c}}$ & $0 \cdot 52 \pm 0 \cdot 1^{b}$ & $0 \cdot 49 \pm 0 \cdot 12^{b}$ \\
\hline Leptin $(\mathrm{ng} / \mathrm{ml})$ & $4 \cdot 0 \pm 0 \cdot 5^{\mathrm{a}}$ & $1 \cdot 8 \pm 0 \cdot 1^{b, c}$ & $3 \cdot 6 \pm 0 \cdot 3^{a}$ & $1 \cdot 3 \pm 0 \cdot 1^{b, c}$ & $1 \cdot 4 \pm 0 \cdot 3^{b}$ \\
\hline C Peptide (pM) & $1268 \cdot 3 \pm 146 \cdot 1^{a}$ & $687 \cdot 3 \pm 128 \cdot 7^{\mathrm{b}, \mathrm{c}}$ & $878 \cdot 6 \pm 124 \cdot 0^{\mathrm{a}, \mathrm{b}, \mathrm{c}}$ & $383 \cdot 8 \pm 37 \cdot 4^{b, c}$ & $488 \cdot 4 \pm 40 \cdot 0^{b}$ \\
\hline $\mathrm{TAG}(\mathrm{mg} / \mathrm{dl})$ & $75 \cdot 9 \pm 10 \cdot 6^{\mathrm{a}}$ & $67 \cdot 3 \pm 10 \cdot 5^{a, b}$ & $73 \cdot 5 \pm 7 \cdot 9^{a, b}$ & $76 \cdot 3 \pm 16 \cdot 0^{a, b}$ & $127 \cdot 8 \pm 12 \cdot 0^{\mathrm{C}}$ \\
\hline $\mathrm{FFA}(\mathrm{mmol} / \mathrm{l})$ & $0.75 \pm 0.02^{a}$ & $0 \cdot 83 \pm 0.03^{a, b, c}$ & $0 \cdot 76 \pm 0 \cdot 02^{\mathrm{a}, \mathrm{c}}$ & $0 \cdot 79 \pm 0 \cdot 01^{\mathrm{a}, \mathrm{b}, \mathrm{c}}$ & $0 \cdot 86 \pm 0 \cdot 02^{b}$ \\
\hline
\end{tabular}

Letters after each value that are not shared mean that the results are significantly different $(P<0 \cdot 05)$.

C-peptide levels in group $\mathrm{M}$ indicate that the improvement in insulin sensitivity does not spare endocrine pancreas from exhaustion. This suggests that the $\beta$-cell damage was not corrected. As adipose tissue is not one of the main targets of metformin action, no improvement was seen in insulin sensitivity in the EP fat. As would be expected with the low insulin levels and the reduced responsiveness to insulin in isolated adipocytes in group $\mathrm{M}$, these treated diabetic animals showed low GLUT4 content in PM and M fractions together with reduced GLUT4 mRNA expression in EP fat pad. Reduced incorporation of glucose into lipids (Fig. 8B) and increased lipolytic activity (Fig. 9) after metformin treatment might have contributed to the lack of recovery of fat mass seen in group $M$ (Fig. 4). As a possible consequence of low fat
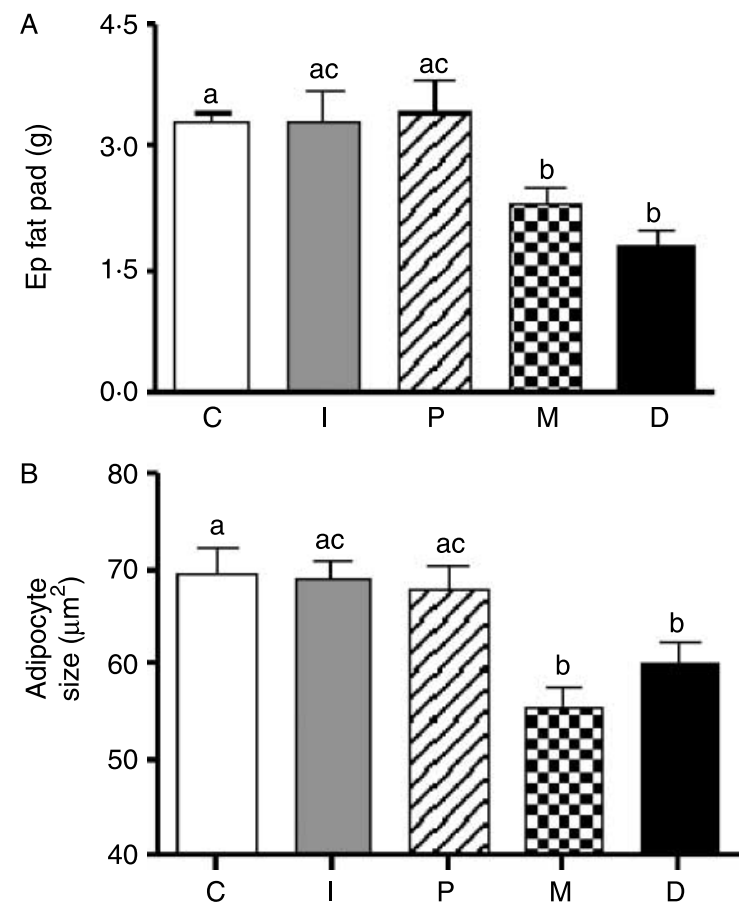

Figure 4 Effect of treatment on adipose mass. (A) Epidydimal (EP) fat pad weight and (B) its cell size. After adipocyte isolation technique (described in Materials and Methods), a sample (100 cells) of adipocytes was used to measure the diameter of in optical microscope $(100 \times)$. Values are mean \pm S.E.M., $n=10$. Letters above bars: see explanation in Fig. 1. mass, leptin levels in group $M$, similar to group D, were significantly reduced. Despite this, metformin was effective in reducing TAG levels. This effect may be attributed to the activation of the AMP-activated protein kinase pathway, possibly in the liver (Velasco et al. 1997).

Long-term treatment with pioglitazone or insulin decreased blood glucose levels significantly; however, it did not completely normalize them. Concurrently, these treatments regularized the food and water intake of the diabetic animals. The improvement in insulin levels can be explained as a consequence of better glycemic control promoted by these treatments. Conversely, C-peptide levels were only partially recovered in group $\mathrm{P}$, without any changes noted in group I. As such, one could conclude that insulin treatment has no effect on C-peptide levels. However, this could be an inhibitory effect of exogenous insulin treatment, attempting to spare the endocrine pancreas from exhaustion. Pancreatic insulin content was fully recovered in groups I and, notably, in P. Pioglitazone as agonist of PPAR $\gamma$ might act directly on pancreatic islets since they express these nuclear receptors (Lupi et al. 2004). Other explanations for the improvement in pancreatic insulin content could be related to the better glycemic control or the anti-lipotoxicity effect of TZDs on $\beta$ cells. As can be seen in Table 2, diabetic rats developed disturbances in lipid metabolism resulting in dyslipidemias with increased TAG and FFA levels. Excessive FFA

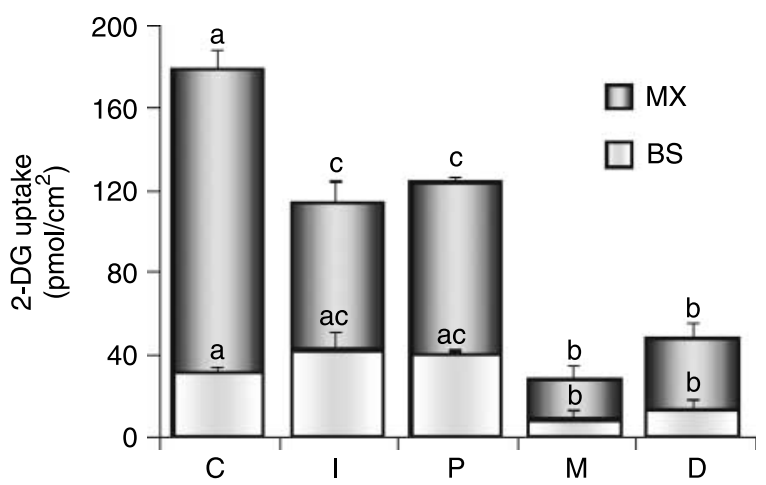

Figure 5 2-Deoxy-glucose uptake in isolated adipocytes. Isolated cells were incubated with (MX) or without (BS) $10 \mathrm{nM}$ insulin for $30 \mathrm{~min}$ at $37^{\circ} \mathrm{C}$ after which a pulse of [3H]-2-DG (185 Bq, 0.4 mM) was added. Uptake reaction was allowed for exactly $3 \mathrm{~min}$. Values are mean \pm S.E.M., $n=10$. Letters above bars: see explanation in Fig. 1. 
A
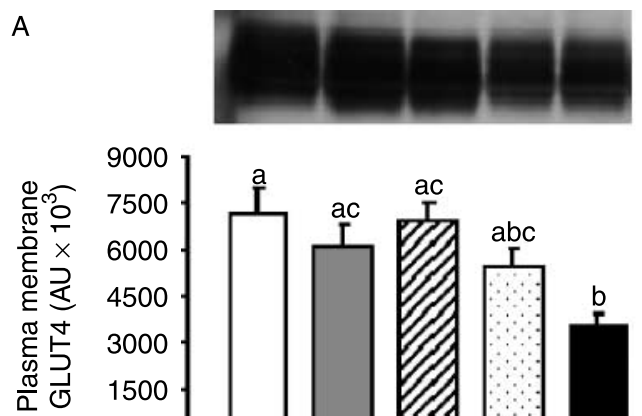
9000
7500
6000
4500
3000
1500 0

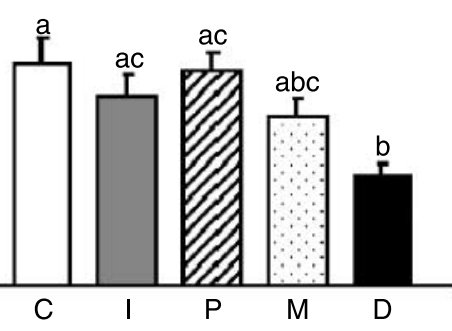

B
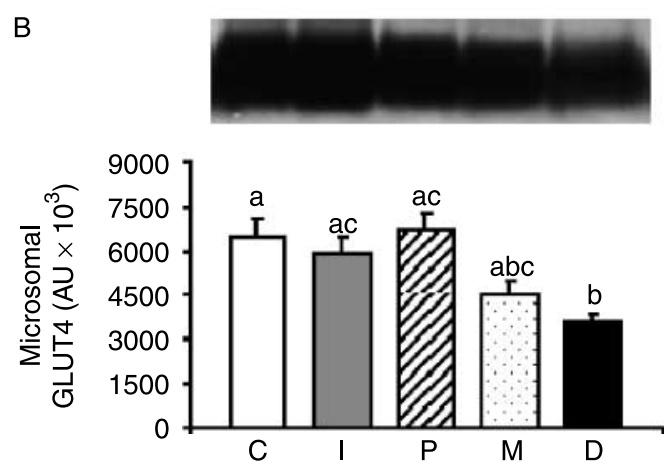

Figure 6 Effect of treatment on GLUT4 protein levels in subcellular membrane fractions of white adipose tissue. (A) Western blot analysis of plasma membrane GLUT4 protein, top: representative blots, bottom: GLUT4 protein value was normalized by the amount of total protein subjected to electrophoresis, and the results are expressed as AU. (B) Western blot analysis of microsomal GLUT4 protein. Top: representative blots, bottom: GLUT4 protein value was normalized by the amount of total protein subjected to electrophoresis, and the results are expressed as AU. Values are mean \pm s.E.M., $n=4-6$. Letters above bars: see explanation in Fig. 1.

mobilization could impair $\beta$-cell function, resulting in proinflammatory and pro-apoptotic results, which contribute to a severe insulin degranulation of the pancreas (Grill \& Björklund 2000). Based on our data, one might conclude that the excessive FFA mobilization from adipose tissue was avoided by $\mathrm{P}$ treatment (Table 2 ), greatly contributing to $\beta$-cell recovery. Furthermore, the improvement on lipid metabolism promoted

Table 3 Effect of treatment on total glucose transporter 4 (GLUT4) content in plasma membrane (PM) and microsomal $(\mathrm{M})$ fractions per epididymal (EP) fat pad weight. Values are mean \pm s.E.M., $n=4-6$

\section{Total GLUT4 content/fat pad weight $(\mathrm{AU} / \mathrm{g})$}

\begin{tabular}{|c|c|c|}
\hline & PM & M \\
\hline Group C & $23648 \cdot 9 \pm 2170 \cdot 0^{a}$ & $21499 \cdot 0 \pm 1780 \cdot 5^{a}$ \\
\hline Group I & $35745 \cdot 0 \pm 5456 \cdot 3^{a}$ & $33440 \cdot 7 \pm 2080 \cdot 5^{c}$ \\
\hline Group P & $23275 \cdot 9 \pm 2798 \cdot 4^{\mathrm{a}}$ & $22484 \cdot 7 \pm 2801 \cdot 8^{a}$ \\
\hline Group M & $10908 \cdot 0 \pm 861 \cdot 4^{b}$ & $9392 \cdot 6 \pm 1308 \cdot 5^{b}$ \\
\hline Group D & $9391 \cdot 0 \pm 1350 \cdot 7^{b}$ & $9771 \cdot 3 \pm 1890 \cdot 9^{b}$ \\
\hline
\end{tabular}

Letters after each value that are not shared mean that the results are significantly different $(P<0 \cdot 05)$.
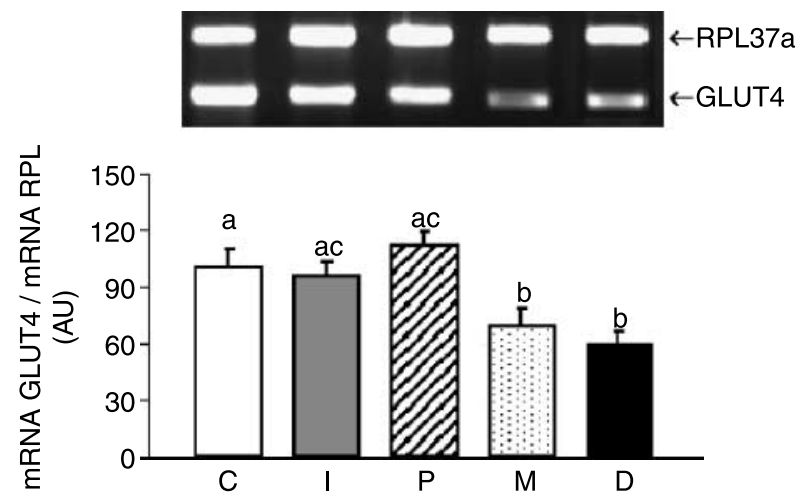

Figure 7 Effect of treatment on GLUT4 mRNA expression. Epididymal adipose tissue was collected from control and diabetic animals with or without treatment. mRNA concentrations were analyzed by RT-PCR. Data were normalized to RPL-37a and expressed as a percent of the value obtained with non-diabetic group. Values are mean \pm s.E.M., $n=8$. Letters above bars: see explanation in Fig. 1 .

by pioglitazone may contribute to good insulin responsiveness, avoiding the accumulation of intracellular lipids in muscle or other extra-adipose tissues that might have resulted in the metabolic abnormalities observed in DM.
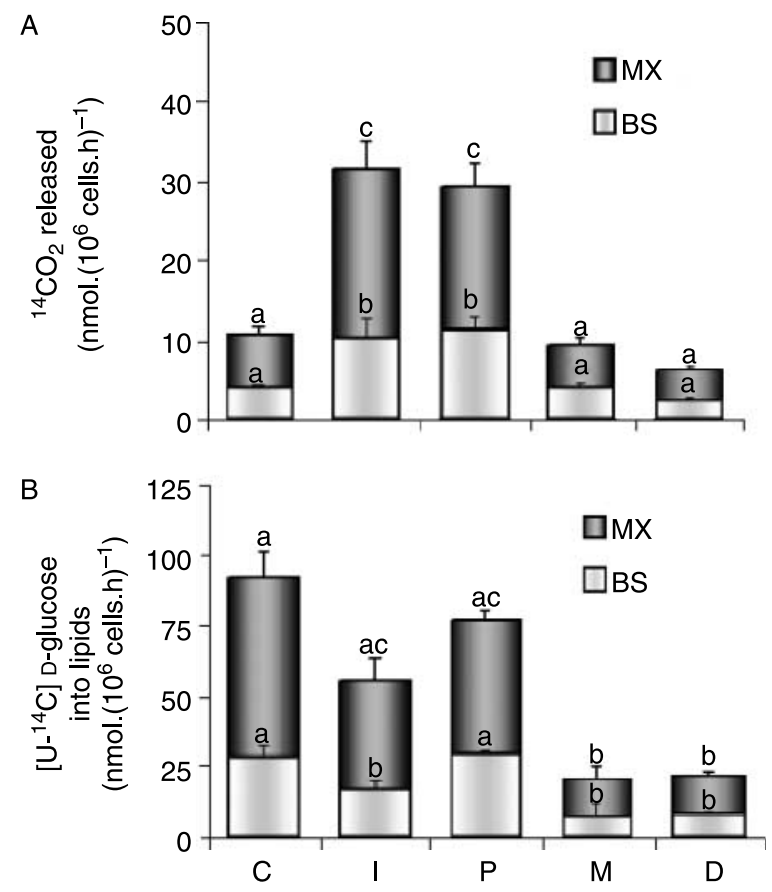

Figure $8\left[\mathrm{U}^{-1}{ }^{14} \mathrm{C}\right]$-glucose conversion to ${ }^{14} \mathrm{CO}_{2}$ and its incorporation into lipids. (A) Adipocytes were isolated and incubated with $\mathrm{D}-\left[\mathrm{U}_{-}{ }^{4} \mathrm{C}\right]$-glucose $(1850 \mathrm{~Bq}, 2 \mathrm{mM})$ with or without insulin for $60 \mathrm{~min}$ at $37^{\circ} \mathrm{C}$. The ${ }^{14} \mathrm{CO}_{2}$ released was collected in an ethanolamineembedded filter paper after addition of $\mathrm{H}_{2} \mathrm{SO}_{4} 8 \mathrm{~N}$. The radioactivity was determined by a scintillation counter. (B) Dole's reagent was added to the remaining mixture for lipid extraction. Values are mean \pm s.E.M., $n=10$. Letters above bars: see explanation in Fig. 1. 


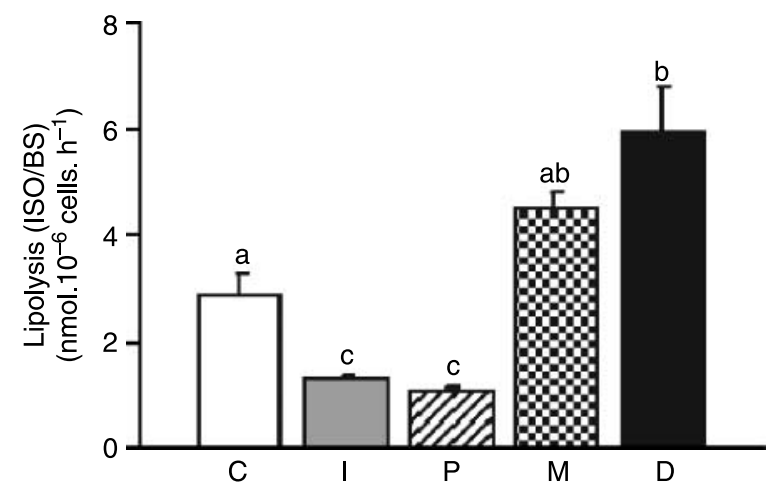

Figure 9 Effect of treatment on lipolysis in isolated adipocytes. Bars represent the ration between isoproterenol-stimulated (ISO) and basal (BS) lipolytic responses. Values are mean \pm S.E.M., $n=10$. Letters above bars: see explanation in Fig. 1.

Although group P did not achieve normal body weight, the Lee index was similar to that of group I, which suggests an improvement in body fat mass of similar magnitude. In group I, this increase is related to the anabolic and anti-lipolytic effects of insulin. Apart from promoting the expression of lipogenic genes, pioglitazone may have influenced the growth and differentiation of pre-adipocytes by raising body adiposity and redistributing lipids in such a way to avoid visceral fat and directing them towards subcutaneous regions, lowering the potential lipotoxicity of visceral depots and improving the insulin sensitivity (Adams et al. 1997). Accordingly, in many studies, TZDs have been shown to reduce visceral adipose mass and to increase the subcutaneous adipose mass (Adams et al. 1997, Miyazaki et al. 2002, Choi et al. 2007). In our work, the TZD effect promoted a 75\% mass increase in EP and SC (data not shown) fat depots. Although not measured, other fat territories may have been affected indicating that a more widespread enhancement has occurred in adiposity. The reduced adipocyte size from group D animals was a result of low insulin levels and insulin resistance that compromised lipogenesis and favored lipolysis. Therefore, the loss of adipose mass in this particular model of DM was very intense, beyond an accepted critical point, leading to a more severe degree of lipodystrophy that could benefit from TZD therapy.

The positive effect in GLUT4 expression in group P was also seen in other studies, which indicates that TZDs exert beneficial effects on insulin resistance by increasing the expression of these glucose transporters in adipose tissue (Sandouk et al. 1993, Furuta et al. 2002). In our work, we also demonstrated that the GLUT4 protein levels presented by group D were even lower when adjusted for total EP fat pad weight. Similarly, the recovery of fat mass in groups I and P accentuated the increase of GLUT4 levels in this adipose depot (Table 3), indicating the critical role of normal insulin levels and ideal fat mass on glucose metabolism in this territory.

Additional data that reinforce the idea of better insulin responsiveness after insulin or pioglitazone treatment are the remarkable increase in glucose oxidation, incorporation into lipids and a drop in lipolysis, which even overcame group C response values. This also explains the recovery of adipose mass and adipocyte size seen in these groups.

The overcorrection in glucose oxidation promoted by $\mathrm{P}$ or I treatments could be explained by an increase in pyruvate dehydrogenase $(\mathrm{PDH})$ activity. The effect of insulin in activating $\mathrm{PDH}$ in adipose tissue is already established (Mukherjee \& Jungas 1975, Stansbie et al. 1976). Our study was the first to check the pioglitazone effect on glucose oxidation in isolated adipocytes. This effect could be related to the improvement on insulin levels. However, no study has evaluated the TZD effect on PDH activity in adipose tissue and therefore, further studies need to be performed to check the mechanisms behind this increase in glucose oxidation promoted by pioglitazone.

As can be seen in Table 2, pioglitazone was the only treatment to restore leptin levels. Interestingly, group I did not show an increase in leptin levels. The role of leptin in metabolism and insulin sensitivity is well established. The lack of leptin or the defect in its action can lead to insulin resistance, dyslipidemias, fatty liver, and diabetes (Van Dijk et al. 2003). However, the low levels of leptin shown in group I may indicate the involvement of other adipokines or tissues (mainly muscle and liver) in the improvement in metabolic parameters evaluated in these animals. On the other hand, the direct effect of insulin on leptin expression remains controversial (Russell et al. 1998, Kanu et al. 2003). Interestingly, in primary adipocyte culture, insulin alone showed no effect on leptin expression. However, in the presence of melatonin, insulin promoted an increase on leptin release, which indicates that insulin interacting synergistically with melatonin produces such a stimulatory effect (AlonsoVale et al. 2005). In the present work, the serum samples were collected in the morning period when melatonin levels are low. This may be a reason for observing no increase in leptin levels in group I.

Our data might not agree with others, where pioglitazone alone did not exert any effect on glucose or lipid metabolism. In STZ-induced diabetic rats in adulthood, a 4-day pioglitazone treatment was unable to improve glucose levels or insulin resistance. However, when pioglitazone was associated with insulin, there was a complete recovery (Ikeda et al. 1990, Hofmann et al. 1991). A reasonable explanation for these discrepancies could be the time of diabetes induction (adulthood against neonatal period) and treatment duration (short $\times$ long term). Furthermore, induction of diabetes during the neonatal period could reflect a more natural progression of this disease, resembling that in human DM.

In this work, we demonstrated that early antidiabetic therapy was capable of partially correcting metabolic abnormalities previously described in this STZ model. All treatments succeeded in significantly reducing, but not normalizing glucose levels. This clearly indicates the participation of other tissues, mainly muscle and liver, on 
glucose homeostasis. Interestingly, when pioglitazone was given to insulin-resistant animals, it promoted a recovery of adipose mass parallel to the improvement of insulin sensitivity and diabetic condition, while metformin was unable to promote any effect on adipose mass and on its insulin sensitivity. These data indicate that the intense reduction of adipose mass in this experimental model plays a significant role in the metabolic condition developed by these animals in adulthood as the recovery of adipose mass corrected considerably the DM metabolic abnormalities.

\section{Declaration of Interest}

The authors declare that there is no conflict of interest that would prejudice the impartiality of this scientific work.

\section{Funding}

This research was supported by National Council of Scientific and Technologic Development (CNPq).

\section{Acknowledgements}

The authors would like to thank Angelo R Carpinelli, Marlene S Rocha, Irene M M Hirai, Erwin Nadich, Rogerio A L Sertié, and Maria Isabel C Alonso-Vale for their technical support.

\section{References}

Adams M, Montague CT, Prins JB, Holder JC, Smith SA, Sanders L, Digby JE, Sewter CP, Lazar MA, Chatterjee VK et al. 1997 Activators of peroxisome proliferator-activated receptor $\gamma$ have depot-specific effects on human preadipocyte differentiation. Journal of Clinical Investigation 100 3149-3153.

Alonso-Vale MI, Andreotti S, Peres SB, Anhê GF, Das Neves Borges-Silva C, Neto JC \& Lima FB 2005 Melatonin enhances leptin expression by rat adipocytes in the presence of insulin. American Journal of Physiology. Endocrinology and Metabolism 288 E805-E812.

Barzilai N, She L, Liu BQ, Vuguin P, Cohen P, Wang J \& Rossetti L 1999 Surgical removal of visceral fat reverses hepatic insulin resistance. Diabetes 48 94-98.

Boden G, Cheung P, Mozzoli M \& Fried SK 2003 Effect of thiazolidinediones on glucose and fatty acid metabolism in patients with type 2 diabetes. Metabolism 52 753-759.

Bonora E, Moghetti P, Zancanaro C, Cigolini M, Querena M, Cacciatori V, Corgnati A \& Muggeo M 1989 Estimates of in vivo insulin action in man: comparison of insulin tolerance tests with euglycemic and hyperglycemic glucose clamp studies. Journal of Clinical Endocrinology and Metabolism 68 374-378.

Borges-Silva CN, Fonseca-Alaniz MH, Alonso-Vale MIC, Takada J, AndreottiS, Peres SB, Cipolla-Neto J, Pithon-Curi TC \& Lima FB 2005 Reduced lipolysis and increased lipogenesis in adipose tissue from pinealectomized rats adpated to training. Journal of Pineal Research 39 178-184.

Choi SH, Zhao ZS, Lee YJ, Kim SK, Kim DJ, Ahn CW, Lim SK, Lee HC \& Cha BS 2007 The different mechanisms of insulin sensitizers to prevent type 2 diabetes in OLETF rats. Diabetes Metabolism Research and Reviews 23 $411-418$.
Chomczynski P \& Sacchi N 1987 Single-step method of RNA isolation by acid guanidinium thiocyanate-phenol-chloroform extraction. Analytical Biochemistry 162 156-159.

DeFronzo RA, Bonadonna RC \& Ferrannini E 1992 Pathogenesis of NIDDM. A balanced overview. Diabetes Care 15 318-368.

Després JP 2003 Potential contribution of metformin to the management of cardiovascular disease risk in patients with abdominal obesity, the metabolic syndrome and type 2 diabetes. Diabetes \& Metabolism 29 6S53-6S61.

Van Dijk G, De Vries K, Benthem L, Nyakas C, Buwalda B \& Scheurink AJ 2003 Neuroendocrinology of insulin resistance: metabolic and endocrine aspects of adiposity. European Journal of Pharmacology 480 31-42.

Fine JB \& Digirolamo M 1997 A simple method to predict cellular density in adipocyte metabolic incubations. International Journal of Obesity and Related Metabolic Disorders 21 764-768.

Fischer-Posovszky P, Wabitsch M \& Hochberg Z 2007 Endocrinology of adipose tissue - an update. Hormone Metabolic Research 39 314-321.

Fonseca V 2003 Effect of thiazolidinediones on body weight in patients with diabetes mellitus. American Journal of Medicine 115 42S-48S.

Furuta M, Yano Y, Gabazza EC, Araki-Sasaki R, Tanaka T, Katsuki A, Hori Y, Nakatani K, Sumida Y \& Adachi Y 2002 Troglitazone improves GLUT4 expression in adipose tissue in an animal model of obese type 2 diabetes mellitus. Diabetes Research Clinical Practice 56 159-171.

Gavrilova O, Marcus-Samuels B, Graham D, Kim JK, Shulman GI, Castle AL, Vinson C, Eckhaus M \& Reitman ML 2000 Surgical implantation of adipose tissue reverses diabetes in lipoatrophic mice. Journal of Clinical Investigation $105271-278$.

Grill V \& Björklund A 2000 Dysfunctional insulin secretion in type 2 diabetes: role of metabolic abnormalities. Cellular and Molecular Life Sciences 57 429-440.

Hofmann C, Lorenz K \& Colca JR 1991 Glucose transport deficiency in diabetic animals is corrected by treatment with the oral antihyperglycemic agente pioglitazone. Endocrinology 129 1915-1925.

Ikeda H, Taketomi S, Sugiyama Y, Shimura Y, Sohda T, Meguro K \& Fujita T 1990 Effects of pioglitazone on glucose and lipid metabolism in normal and insulin resistant animals. Arzneimittel-Forschung 40 156-162.

Kanu A, Fain JN, Bahouth SW \& Cowan GS 2003 Regulation of leptin release by insulin, glucocorticoids, $G(i)$-coupled receptor agonists, and pertussis toxin in adipocytes and adipose tissue explants from obese humans in primary culture. Metabolism $\mathbf{5 2}$ 60-66.

Kelley DE, Goodpaster BH \& Storlien L 2002 Muscle triglyceride and insulin resistance. Annual Review of Nutrition 22 325-346.

Lacy PE \& Kostianovsky M 1967 Method for the isolation of intact islets of Langerhans from the rat pancreas. Diabetes 16 35-39.

Lebovitz HE, Banerji MD \& Chaiken RL 1995 The relationship between type II diabetes and syndrome X. Current Opinion in Endocrinology and Diabetes 2 307-312.

Lupi R, Del Guerra S, Marselli L, Bugliani M, Boggi U, Mosca F, Marchetti P \& Del Prato S 2004 Rosiglitazone prevents the impairment of human islet function induced by fatty acids: evidence for a role of PPAR $\gamma 2$ in the modulation of insulin secretion. American Journal of Physiology. Endocrinology and Metabolism 286 E560-E567.

Maggs DG, Buchanan TA, Burant CF, Cline G, Gumbiner B, Hsueh WA, Inzucchi S, Kelley D, Nolan J, Olefsky JM et al. 1998 Metabolic effects of troglitazone monotherapy in type 2 diabetes mellitus. A randomized, doubleblind, placebo-controlled trial. Annals of Internal Medicine 128 176-185.

Miyazaki Y, Mahankali A, Matsuda M, Mahankali S, Hardies J, Cusi K, Mandarino LJ \& DeFronzo RA 2002 Effect of pioglitazone on abdominal fat distribution and insulin sensitivity in type 2 diabetic patients. Journal of Clinical Endocrinology and Metabolism 87 2784-2791.

Mukherjee C \& Jungas RL 1975 Activation of pyruvate dehydrogenase in adipose tissue by insulin. Biochemical Journal 148 229-235.

Natali A \& Ferrannini E 2006 Effects of metformin and thiazolidinediones on suppression of hepatic glucose production and stimulation of glucose uptake in type 2 diabetes: a systematic review. Diabetologia 49 434-441.

Okamoto MM, Sumida DH, Carvalho CRO, Vargas AM, Heimann JC, Schaan BD \& Machado UF 2004 Changes in dietary sodium consumption modulate GLUT4 gene expression and early steps of insulin signalling. American Journal of Physiology Regulatory, Integrative and Comparative Physiology 286 R779-R785. 
Okuno A, Tamemoto H, Tobe K, Ueki K, Mori Y, Iwamoto K, Umesono K, Akanuma Y, Fujiwara T, Horikoshi H et al. 1998 Troglitazone increases the number of small adipocytes without change of white adipose tissue mass in obese Zucker rats. Journal of Clinical Investigation 101 1354-1361.

Parulkar AA, Pendergrass ML, Granda-Ayala R, Lee TR \& Fonseca VA 2001 Nonhypoglycemic effects of thiazolidinediones. Annals of Internal Medicine $13461-71$.

Randle PJ, Garland PB, Hales CN \& Newsholme EA 1963 The glucose-fattyacid cycle. Its role in insulin sensitivity and the metabolic disturbances of diabetes mellitus. Lancet 1 785-789.

Rodbell M 1964 Metabolism of isolated fat cells. Effects of hormones on glucose metabolism and lipids. Journal of Biological Chemistry 239 357-380.

Russell CD, Petersen RN, Rao SP, Ricci MR, Prasad A, Zhang Y, Brolin RE \& Fried SK 1998 Leptin expression in adipose tissue from obese humans: depot-specific regulation by insulin and dexamethasone. American Journal of Physiology. Endocrinology and Metabolism 275 E507-E515.

Sandouk T, Reda D \& Hofmann C 1993 The antidiabetic agente pioglitazone increases expression of glucose transporters in 3T3-F442A cells by increasing messenger ribonucleic acid transcript stability. Endocrinology 133 352-359.

Setter SM, Iltz JL, Thams J \& Campbell RK 2003 Metformin hydrochloride in the treatment of type 2 diabetes mellitus: a clinical review with a focus on dual therapy. Clinical Therapeutics 25 2991-3026.

Sharma AM \& Staels B 2007 Review: peroxisome proliferator-activated receptor gamma and adipose tissue-understanding obesity-related changes in regulation of lipid and glucose metabolism. Journal of Clinical Endocrinology and Metabolism 92 386-395.

Song S 2002 The role of increased liver triglyceride content: a culprit of diabetic hyperglycaemia. Diabetes Metabolism Research and Reviews 18 5-12.
Stansbie D, Denton RM, Bridges BJ, Pask HT \& Randle PJ 1976 Regulation of pyruvate dehydrogenase and pyruvate dehydrogenase phosphate phosphatase activity in rat epididymal fat-pads. Biochemical Journal 154 225-236.

Takada J, Machado MA, Peres SB, Brito LC, Borges-Silva CN, Costa CEM, Fonseca-Alaniz MH, Andreotti S \& Lima FB 2007 Neonatal streptozotocin-induced diabetes mellitus: a model of insulin resistance associated with loss of adipose mass. Metabolism 56 977-984.

Tontonoz P, Hu E \& Spiegelman BM 1994 Stimulation of adipogenesis in fibroblasts by PPAR gamma2, a lipid-activated transcription factor. Cell 79 1147-1156.

Velasco G, Geelen NJ \& Guzmán M 1997 Control of hepatic fatty acid oxidation by $5^{\prime}$-AMP-activated protein kinase involves a malonyl-CoA dependent and a malonyl-CoA-independent mechanism. Archives of Biochemistry and Biophysics 337 169-175.

Wilding J 2006 Thiazolidinediones, insulin resistance and obesity: finding a balance. International Journal of Clinical Practice 60 1272-1280.

Wu MS, Johnston P, Sheu WH, Hollenbeck CB, Jeng CY, Goldfine ID, Chen YD \& Reaven GM 1990 Effect of metformin on carbohydrate and lipoprotein metabolism in NIDDM patients. Diabetes Care 13 1-8.

\section{Received in final form 25 April 2008}

Accepted 30 April 2008

Made available online as an Accepted Preprint

1 May 2008 